\title{
Flavonóides e composição mineral de folhas de maracujazeiro amarelo em função da posição da folha no ramo
}

\author{
Flavonoids and mineral composition the leaf in yellow passion fruit plant in function of leaves at \\ positions in the branch
}

\author{
Marta Simone Mendonça Freitas ${ }^{\mathrm{I}}$ Pedro Henrique Monnerat ${ }^{\mathrm{II}}$ Ivo José Curcino Vieira ${ }^{\mathrm{III}}$ Almy Júnior \\ Cordeiro de Carvalho ${ }^{\mathrm{II}}$
}

\section{RESUMO}

Este trabalho foi realizado em maracujazeiro amarelo (Passiflora edulis Sims $\boldsymbol{f}$. flavicarpa) cultivado em condições de campo, no município dos Campos do Goytacazes$R J$, com o objetivo de determinar os teores de rutina, vitexina e flavonóides totais e dos nutrientes $\mathrm{N}, \mathrm{P}, \mathrm{K}, \mathrm{Ca}, \mathrm{Mg}, \mathrm{S}, \mathrm{B}, \mathrm{Fe}$, $\mathrm{Zn}, \mathrm{Mn}$ e $\mathrm{Cl}$ em folhas de diferentes posição no ramo. $O$ experimento constou de 10 tratamentos, que consistiam na coleta das folhas 1 (mais nova) a 10 (mais velha) de um mesmo ramo, com quatro repetições. A amostragem foliar foi feita em março de 2004 e cada amostra constou de 20 folhas coletadas de 20 plantas por repetição. Os teores de rutina, vitexina e flavonóides totais variaram em função da posição ou idade das folhas, sendo maiores nas folhas mais jovens ou na região apical dos ramos do maracujazeiro amarelo. Os teores de flavonóides totais, expressos em vitexina, diminuíram da folha 1 para a folha 8 , de 24,4 para 14,9mg $\mathrm{g}^{-1}$ de matéria seca. Os teores de $N, P, K$ e $\mathrm{Zn}$ foram maiores e os de Ca, Mg, $B, C l$ e Mn foram menores nas folhas mais jovens. Os teores de $\mathrm{S}$ e Fe não variaram com a posição da folha no ramo.

Palavras-chave: Passiflora edulis Sims $\boldsymbol{f}$. flavicarpa, nutrição mineral, rutina, vitexina.

\section{ABSTRACT}

The research was carried out in yellow passion fruit plant (Passiflora edulis Sims $\boldsymbol{f}$. flavicarpa) grown under field conditions in Campos dos Goytacazes-RJ, Brazil, with the aim to evaluate the concentrations of rutin, vitexin, total flavonoids, $\mathrm{N}, \mathrm{P}, \mathrm{K}, \mathrm{Ca}, \mathrm{Mg}, \mathrm{S}, \mathrm{B}, \mathrm{Fe}, \mathrm{Zn}, \mathrm{Mn}$ and $\mathrm{Cl}$ in leaves at different positions in the branch. The experiment consisted of 10 treatments: leaves 1 (the youngest) to 10 (the olderest) of the same branch, with four replicates. Leaf sampling was done in March 2004, and each sample consisted of 20 leaves from 20 plants. The total concentration of rutin, vitexin and total flavonoids varied in function of the position or age of leaves, being higher in youngest leaves or in the aplical region of the plant branches. The total flavonoids concentration decreased from leaf 1 to leaf 8 of the branch 24.4 and $14.9 \mathrm{mg} \mathrm{g}^{-1}$ of dry matter, respectively. The concentrations of $N, P, K$ and $\mathrm{Zn}$ were higher in the youngest leaf but the concentrations of $\mathrm{Ca}, \mathrm{Mg}, \mathrm{B}$, $\mathrm{Cl}$ and $\mathrm{Mn}$ were lower. The concentrations of $\mathrm{S}$ and Fe did not vary with leaves positions in the branch.

Key words: Passiflora edulis Sims, mineral nutrition, rutin, vitexin.

\section{INTRODUÇÃO}

As espécies de Passiflora, além de fornecerem o suco extraído dos seus frutos, podem ser utilizadas como ornamentais e medicinais. Como medicinais, as folhas secas de Passiflora incarnata, Passiflora alata e Passiflora edulis podem ser empregadas no tratamento de ansiedade e nevralgia (SOULIMAI et al., 1997) e possuem atividade ansiolítica (PARIS et al., 2002). Os constituintes químicos das folhas de espécies de Passiflora são: flavonóides, alcalóides, glicosídeos, fenóis e terpenos (PEREIRA \& VILLEGAS, 2000; DHAWAN et al., 2004). Em folhas de Passiflora edulis, MORAES (1995) identificou os flavonóides rutina, vitexina e orientina.

Estudando compostos fenólicos em folha de Copaifera langsdorffii, em diferentes idades, LANGENHEIM et al. (1986) verificaram que a concentração desses compostos foi maior em folhas mais novas.

ILaboratório de Solos, Universidade Estadual do Norte Fluminense Darcy Ribeiro (UENF), 28015-620, Campos dos Goytacazes,

RJ, Brasil. E-mail: msimone@uenf.br. Autor para correspondência.

"Laboratório de Fitotecnia, UENF, Campos dos Goytacazes, RJ, Brasil.

IIILaboratório de Química de Produtos Naturais, UENF, Campos dos Goytacazes, RJ, Brasil. 
Com relação aos nutrientes foliares, os teores podem variar em função da idade ou da posição da folha amostrada; entretanto, a direção da variação depende do nutriente e da espécie em estudo. Segundo MARSCHNER (1995), os nutrientes mais móveis no floema, tais como o N, o P e o K, tendem a diminuir com a idade das folhas e apresentarem-se em menores teores nas folhas mais distantes da região apical dos ramos. Por outro lado, verifica-se em nutrientes pouco móveis, tais como o Ca, o B e o Mn, normalmente, um efeito contrário. Trabalho realizado por SANTOS (2002) com coqueiro anão verde mostra que os teores de $\mathrm{Ca}, \mathrm{Mg}$, Fe e Mn aumentaram das folhas mais novas para as mais velhas e o oposto ocorreu com os teores de $\mathrm{P}, \mathrm{K}$, $\mathrm{Cu}$ e $\mathrm{Zn}$. Para N, houve acréscimo até a folha 6 e posterior decréscimo nas folhas mais velhas; para B, houve decréscimo da folha 1 até a folha 6 e depois incremento até a folha 18.

Para Passiflora edulis Sims f. flavicarpa, espécie de grande interesse comercial no Brasil, que é popularmente conhecida como maracujazeiro amarelo e possui mais de 30.000ha cultivados, não se conhece o comportamento dos nutrientes em função da posição da folha no ramo, que é fundamental para os programas de avaliação do estado nutricional da planta, notadamente na determinação da folha a ser amostrada para diagnose foliar. Além disso, praticamente não se conhece, nas diferentes regiões do Brasil e em condições de campo, os teores dos flavonóides rutina e vitexina nas plantas. Tal fator é importante porque existe a possibilidade de comercialização, para indústrias de fitoterápicos, de folhas provenientes de podas, uma prática cultural comum a esta espécie, o que já vem sendo feito por alguns produtores.

Nesse sentido, o presente trabalho teve como objetivo avaliar o efeito da posição da folha no ramo do maracujazeiro amarelo sobre os teores de vitexina, rutina, flavonóides totais e de nutrientes minerais.

\section{MATERIAL E MÉTODOS}

Este trabalho foi realizado em Campos dos Goytacazes-RJ, com folhas coletadas em lavoura comercial de maracujazeiro amarelo (Passiflora edulis Sims f. flavicarpa Deg.). O plantio das mudas no campo ocorreu em novembro de 2002, em Argissolo Amarelo distrófico, com espaçamento de 3,5 x 2,0m. O sistema de condução da cultura foi do tipo espaldeira. A adubação de plantio foi realizada com $1,5 \mathrm{~kg}$ de esterco de galinha, 16 g de N, 24,5g de P, 26,6g de K e 200g de calcário dolomítico por cova. A adubação de formação foi realizada em cobertura aos 60 e 120 dias após o plantio, com 35g de N, 1,3g de Pe 37,4g de K por planta, em cada época. As plantas foram irrigadas por gotejamento.

Para amostragem de folhas, a área experimental foi separada em quatro fileiras de plantio, com 20 plantas cada uma, sendo que cada fileira constituiu uma repetição. Em cada planta, de cada repetição, foi selecionado um ramo, de onde foram colhidas, separadamente, as folhas de 1 (mais jovem) a 10 (mais velha), que constituíam os tratamentos. Cada amostra foi composta por 20 folhas. Considerou-se como número $1 \mathrm{a}$ folha com cerca de $3 \mathrm{~cm}$ de largura (Figura 1).

As diferenças entre as posições das folhas no ramo, para as variáveis quantificadas, foram estatisticamente avaliadas pelo teste de $\mathrm{F}$ ao nível de 5\% de probabilidade. Em caso de significância, para cada variável, o comportamento foi analisado utilizandose regressão polinomial. Utilizou-se, para análise, o sistema operacional SANEST.

A coleta das folhas, sem pecíolo, foi realizada em março/2004, em plantas com 18 meses de idade. As folhas foram acondicionadas em sacos de papel Kraft, secadas em estufa com circulação forçada de ar à temperatura de $45^{\circ} \mathrm{C}$, durante 72 horas, e moídas em moinho com peneira de 30 mesh. Determinaram-se, nas amostras, o N, pelo método de Nessler (JACKSON, 1965); o P, por colorimetria; o K, por fotometria de chama; Ca, Mg, Fe, Zn e Mn, por espectrofotometria de absorção atômica; o S, por turbidimetria com cloreto de bário; o $\mathrm{Cl}$, por titulometria com nitrato de prata e o B, pelo método da Azometina-H (MALAVOLTA et al., 1997).

Para determinação dos flavonóides rutina e vitexina, utilizou-se metodologia descrita por PEREIRA (2002) com adaptações: na primeira etapa, $1 \mathrm{~g}$ de folha do maracujazeiro amarelo, secada e moída, foi submetido à extração com $10 \mathrm{~mL}$ de metanol em agitador, durante 24 horas, à temperatura ambiente. Após esse período, os extratos foram filtrados, utilizando-se papel de filtro de filtração rápida, e recolhidos em béquer de $50 \mathrm{~mL}$, que foi colocado em capela de exaustão para evaporar o metanol, obtendo-se o extrato concentrado. Na segunda etapa, o extrato foi diluído com $2 \mathrm{~mL}$ de metanol:água na proporção de 2:1 e introduzido em cartucho Sep-Pak (Waters), com fase estacionária C-18 e eluído seqüencialmente com: a) $10 \mathrm{~mL}$ de metanol $60 \%$; b) $5 \mathrm{~mL}$ de metanol $80 \%$ e $25 \mathrm{~mL}$ de metanol puro. $\mathrm{Na}$ terceira etapa, o extrato eluído na fração metanol 60\%, recolhido em béquer de $50 \mathrm{~mL}$, previamente secado e pesado, foi colocado em banho de areia a $50^{\circ} \mathrm{C}$, em capela de exaustão. Após esse procedimento, o béquer, com o material seco, foi pesado e calculou-se a 


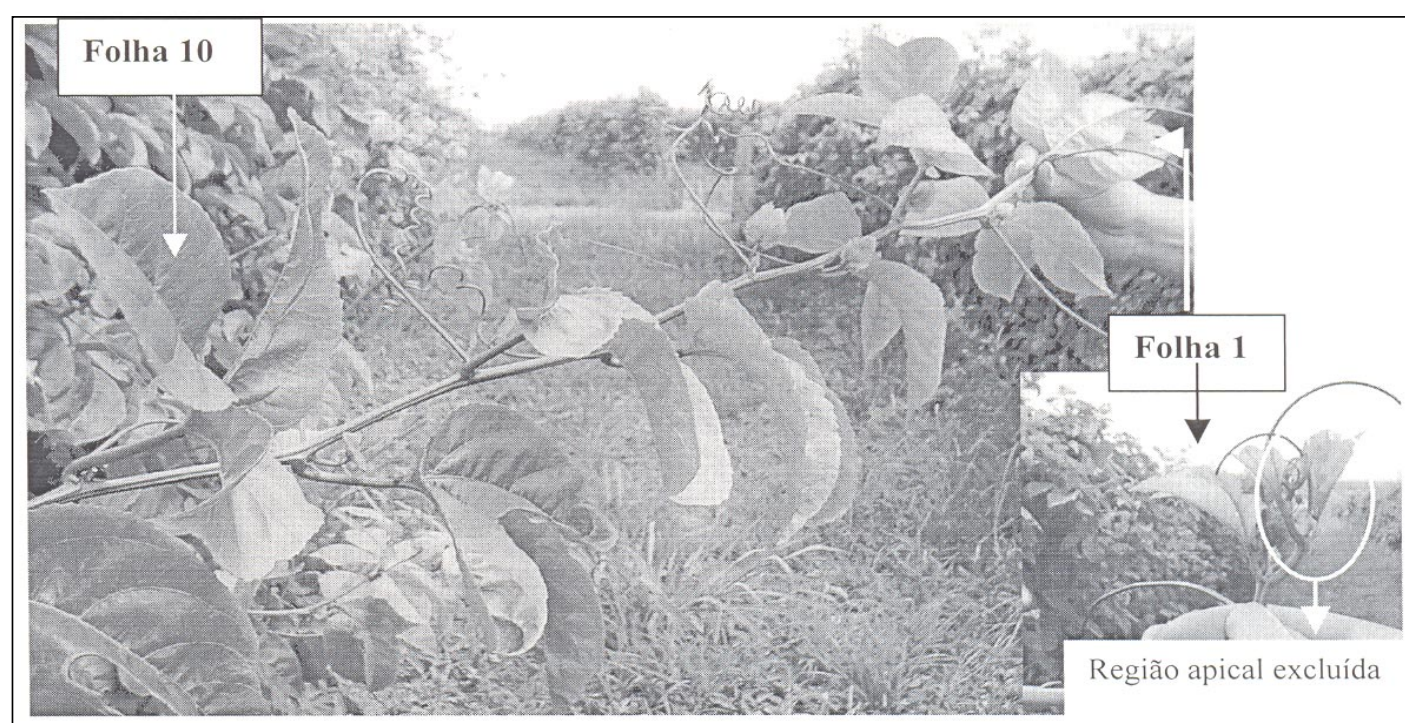

Figura 1 - Visão geral de um ramo do maracujazeiro amarelo com indicação da Folha 1 e da Folha 10 e da região apical de crescimento do ramo que era eliminada em cada amostragem.

quantidade de flavonóides na fração. Na quarta etapa, esses extratos foram diluídos com $8 \mathrm{~mL}$ de metanol: água

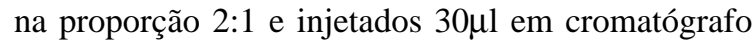
líquido Shimadzu equipado com coluna C-18. As condições cromatográficas foram: fluxo de $0,8 \mathrm{~mL}$, fase móvel constituída por solvente A (ácido fórmico 2\%) e solvente $B$ (acetonitrila), gradiente de eluição: 0-10 minutos $15 \%$ de $B$ em A, 10-40 minutos 15-30\% de B em Ae de $40-45$ minutos $30-15 \%$ de $B$ em A.

Para a análise quantitativa dos flavonóides rutina e vitexina, utilizou-se o método do padrão externo, empregando-se vitexina da marca Fluka ${ }^{\circledR}$ e rutina da marca Aldrich ${ }^{\circledast}$ como referências. As soluções-padrão foram preparadas em metanol e injetadas nas mesmas condições das amostras. Com as áreas e as concentrações foram montadas as equações, do tipo y $=\mathrm{a}+\mathrm{bx}$, em que $\mathrm{y}=$ concentração e $\mathrm{x}=$ área. As áreas das amostras foram introduzidas nessa equação e obtidas as respectivas concentrações em $\mathrm{mg} \mathrm{mL}^{-1}$, que, ao final, foram multiplicadas por 8 para se obterem as concentrações de rutina e vitexina em $\mathrm{mg} \mathrm{g}^{-1}$ de matéria seca. Os flavonóides totais, expressos em vitexina, foram calculados substituindo-se a área total de cada amostra na equação.

\section{RESULTADOS E DISCUSSÃO}

Analisando as equações da figura 2A e 2B, é possível verificar que os teores de rutina e vitexina nas folhas do maracujazeiro amarelo estimados decresceram, aproximadamente, até a 8a e a $9^{a}$ folhas, respectivamente. Em relação à folha 1, o teor estimado de rutina na matéria seca da folha 8 passou de 5,91 para 3,58mg g ${ }^{-1}$ de matéria seca (Figura 2A), num decréscimo de 39,5\%; para a vitexina, o teor diminuiu, da folha 1 para a folha 9 , de 1,33 para $0,75 \mathrm{mg} \mathrm{g}^{-1}$ de matéria seca (Figura 2B), com redução de 42,8\%. Os teores de flavonóides totais expressos em vitexina decresceram da folha 1 para a folha 8, de 24,4 para $14,9 \mathrm{mg} \mathrm{g}^{-1}$ de matéria seca, com redução de $39,1 \%$ (Figura 2C).

Não foram encontradas informações sobre a influência da posição da folha sobre os teores de flavonóides em plantas. Os resultados encontrados no presente trabalho para teores de rutina, vitexina e flavonóides totais (Figura 2) assemelham-se aos encontrados para compostos fenólicos em folhas de Copaifera langsdorffii por LANGENHEIM et al. (1986) e para o alcalóide camptothecin (CPT) em folhas de Camptotheca acuminata por LIU et al. (1998). Segundo esses últimos o mecanismo de maior concentração de princípios ativos nas folhas mais jovens pode ser uma estratégia programada da defesa, que evolui de modo que a folha jovem seja protegida por produtos químicos de defesa durante seu desenvolvimento ontogênico normal, pois possuem estrutura física macia, característica que pode fazê-las atrativas aos ataques de herbívoros.

A tabela 1 apresenta a distribuição percentual dos flavonóides totais, vitexina e rutina contidos nas folhas do ramo do maracujazeiro amarelo, estimada pela equação das figuras $2 \mathrm{~A}, 2 \mathrm{~B}$ e $2 \mathrm{C}$. No presente trabalho, se fossem coletadas as cinco folhas mais novas do ramo de maracujazeiro, elas conteriam 


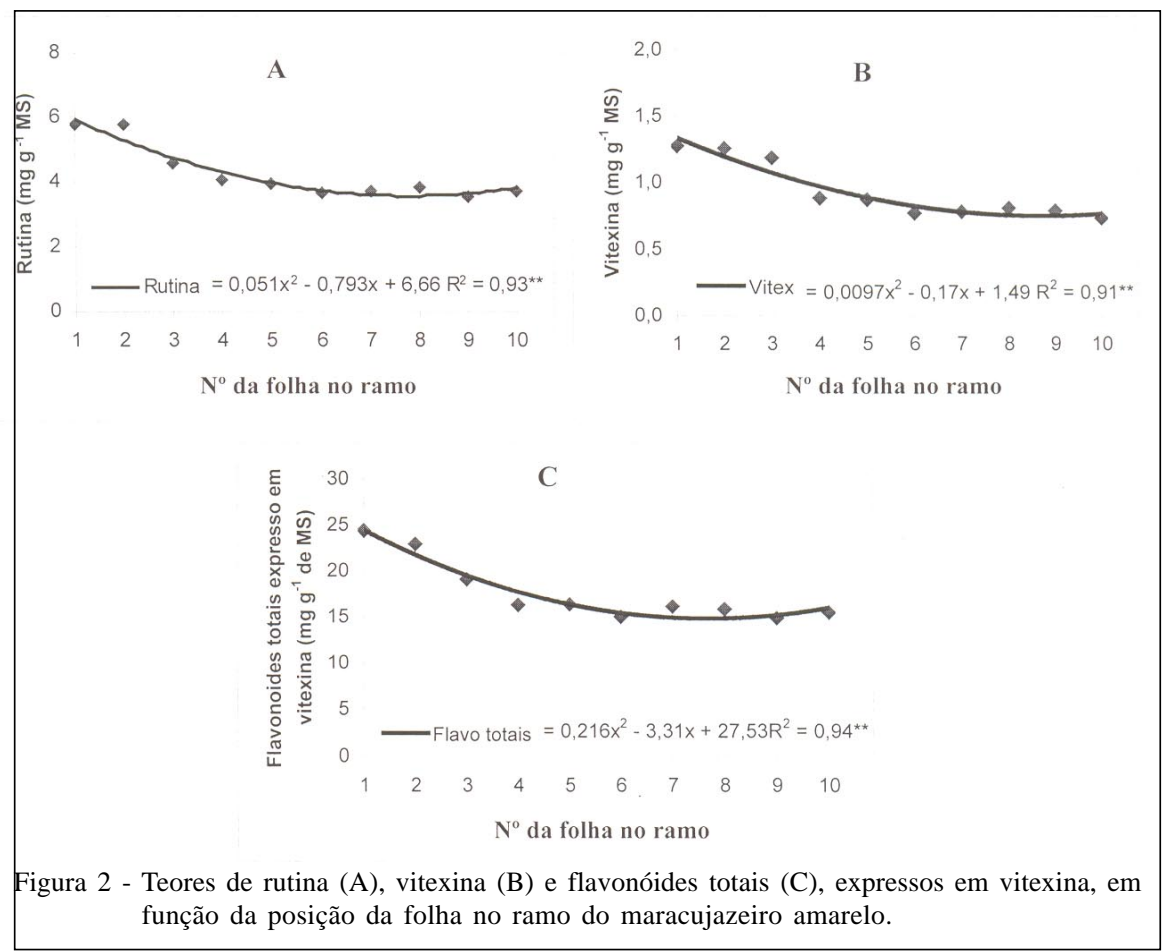

apenas 38,4\% dos flavonóides totais, ao passo que as cinco mais velhas conteriam $61,6 \%$ dos flavonóides do ramo. A mesma tendência ocorreu para rutina e vitexina (Tabela1).

Os teores de flavonóides totais encontrados nas dez folhas do ramo do maracujazeiro amarelo variaram de 24,4 a 14,9 $\mathrm{mg} \mathrm{g}^{-1}$ de matéria seca (Figura 2C). Para a Farmacopéia Européia, órgão Oficial Farmacêutico Europeu onde se estabelece a qualidade dos medicamentos em uso na Europa, espécies de Passiflora devem ter um mínimo de $15 \mathrm{mg} \mathrm{g}^{-1}$ de flavonóides totais na matéria seca, expressos em vitexina, para serem utilizadas na produção de fitoterápicos. PEREIRA (2002) encontrou teores de flavonóides totais, expressos em vitexina, de 11,05 e $17 \mathrm{mg} \mathrm{g}^{-1}$ de matéria seca em folhas de Passiflora edulis coletadas em junho, na cidade de Ribeirão Preto-SP e em Minas Gerais, respectivamente. O autor não mencionou quais folhas foram coletadas para a realização dessas análises.

A composição mineral em relação à posição da folha no ramo do maracujazeiro amarelo é apresentada na figura 3. Analisando a figura 3A, é possível mostrar que os teores de $\mathrm{N}$ nas folhas do maracujazeiro amarelo decresceram, aproximadamente, até a 8 a folha, comportamento semelhante ao

Tabela 1 - Peso de matéria seca da folha e distribuição percentual dos flavonóides totais, vitexina e rutina, no ramo do maracujazeiro amarelo.

\begin{tabular}{ccccc}
\hline Número da folha & Matéria seca por folha $(\mathrm{g})$ & $\begin{array}{c}\text { Distribuição percentual de } \\
\text { flavonóides totais em relação } \\
\text { às folhas do ramo (\%) }\end{array}$ & $\begin{array}{c}\text { Distribuição percentual de } \\
\text { vitexina em relação às folhas } \\
\text { do ramo (\%) }\end{array}$ & $\begin{array}{c}\text { Distribuição percentual de } \\
\text { rutina em relação às folhas do } \\
\text { ramo (\%) }\end{array}$ \\
\hline 1 & 0,14 & 3,7 & 3,9 & 3,7 \\
2 & 0,25 & 5,9 & 9,2 & 5,9 \\
3 & 0,41 & 8,6 & 10,1 & 9,7 \\
4 & 0,50 & 9,6 & 9,9 & 9,6 \\
5 & 0,54 & 9,6 & 11,5 & 11,2 \\
7 & 0,67 & 11,2 & 11,0 & 11,0 \\
9 & 0,68 & 11,0 & 12,7 & 13,0 \\
10 & 0,81 & 13,0 & 12,8 & 13,4 \\
\hline
\end{tabular}

Ciência Rural, v.37, n.6, nov-dez, 2007. 

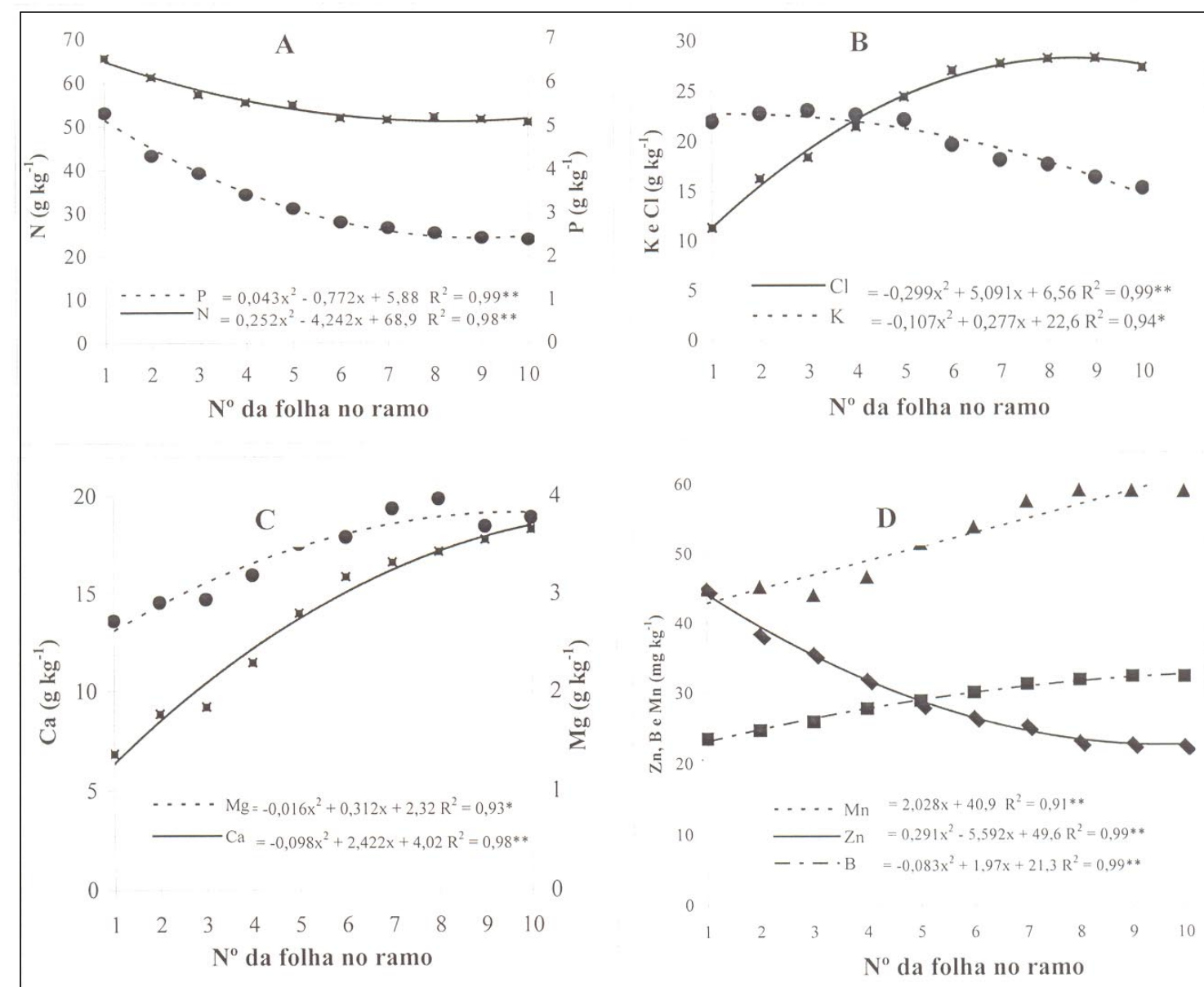

Figura 3 - Teores de nitrogênio $(\mathrm{N})$, fósforo $(\mathrm{P})$, potássio $(\mathrm{K})$, cloro $(\mathrm{Cl})$, cálcio $(\mathrm{Ca})$, magnésio $(\mathrm{Mg})$, boro $(\mathrm{B})$, manganês (Mn) e zinco (Zn) em função da posição da folha no ramo do maracujazeiro amarelo.

observado para os teores de rutina e vitexina. O decréscimo no teor de $\mathrm{N}$ da folha 1 para a folha 8 foi de $25 \%$, decréscimo proporcionalmente menor do que aquele observado para os teores de rutina (Figura 2A) e vitexina (Figura 2B). LANGENHEIM et al. (1986) encontraram, em folhas de Copaifera langsdorffi, resultados semelhantes para teores de N. Essa tendência não é geral entre as espécies, pois SANTOS (2002) observou em coqueiro anão verde aumento no teor de $\mathrm{N}$ da folha 1 até a folha 6 e depois uma redução constante até a folha 18 .

Os teores de P (Figura 3A), K (Figura 3B) e Zn (Figura 3D) foram maiores nas folhas novas, assim como observado para $\mathrm{N}$, rutina e vitexina. Os teores de P nas folhas decresceram em $53 \%$ da folha 1 até a folha 9. Para o K e o Zn, observaram-se decréscimos na ordem de $35,6 \%$ e $48,5 \%$, respectivamente, entre os teores estimados na folha 1 com aqueles estimados na folha 10. O P e o K são nutrientes considerados bastante móveis no floema, sendo redistribuídos a partir de órgãos mais velhos para órgãos novos, o que está de acordo com informações de MARSCHNER (1995), MALAVOLTA et al., (1997), SANTOS (2002) e LEITÃO \& SILVA(2004). Para o Zn, MALAVOLTA et al. (1997) afirmam que este nutriente é pouco móvel no floema das plantas, ou seja, era de se esperar maior concentração deste nutriente nas folhas mais velhas do maracujazeiro amarelo. Os resultados obtidos pode sugerir que o $\mathrm{Zn}$ apresenta maior mobilidade nas folhas do maracujazeiro amarelo.

Para o Cl (Figura 3B), o Ca e o Mg (Figura 3C) e para o Mn e o B (Figura 3D), verificou-se incremento nos teores com o aumento da posição da folha do ápice para a base no ramo terciário do maracujazeiro amarelo. No intervalo estudado, ou seja, da folha 1 até a folha 10, estimou-se, com base nos resultados encontrados, que os teores de $\mathrm{Cl}$, nas folhas do maracujazeiro amarelo, aumentaram em $143 \%$ e os do Mg em 46,8\%. MARSCHNER (1995) afirma que estes nutrientes são móveis no floema das plantas e, 
neste sentido, era de se esperar que os teores fossem maiores nas folhas mais jovens, assim como observado para N, P e K. O incremento nos teores de Ca e Mn da folha 1 (a mais nova) para a folha 10 (a mais velha) do maracujazeiro foi estimado em $190 \%$ e $42,5 \%$, respectivamente, o que está de acordo com a baixa mobilidade desses nutrientes no floema das plantas e com a tendência de se acumular nas folhas mais velhas, segundo MARSCHNER (1995).

O aumento no teor de B da folha 1 para a folha 10 foi estimado em 40,9\%, passando de 23,2 $\mathrm{mg} \mathrm{kg}^{-1}$ para 32,7 $\mathrm{mg} \mathrm{kg}^{-1}$ na matéria seca foliar do maracujazeiro amarelo (Figura 3D). DALE \& KRYSTYNA (1998) concluíram que a mobilidade do boro no floema depende da presença de polióis (manitol, sorbitol, etc.), o que ainda não foi estudado no maracujazeiro amarelo. Trabalhando com folhas maduras de Olea europaea em idades diferentes, FERNANDEZ-ESCOBAR et al. (1999) obtiveram maior teor de B em folhas novas. Esses autores relatam que em Olea europaea L. o B é mobilizado das folhas para flores e frutos. Para o coqueiro, SANTOS (2002) observou que o teor de B decresceu da folha 1 até a 6 e aumentou até a folha 18 .

Para os nutrientes Fe e $\mathrm{S}$ não se verificou variação significativa nos teores entre as folhas analisadas. Para o Fe, os teores médios observados foram de $95 \mathrm{mg} \mathrm{kg}^{-1}$ de matéria seca e os de $\mathrm{S}$ foram de $4,46 \mathrm{~g} \mathrm{~kg}^{-1}$ de matéria seca.

\section{CONCLUSÕES}

Os teores de rutina, vitexina e flavonóides totais são maiores nas folhas mais jovens do maracujazeiro amarelo, demonstrando a possibilidade de utilização de folhas das podas do maracujazeiro amarelo, principalmente as mais novas, para a produção de fitoterápicos. Maiores teores de N, P, K e Zn foram encontrados nas folhas jovens e de $\mathrm{Ca}, \mathrm{Mg}, \mathrm{B}, \mathrm{Cl}$ e $\mathrm{Mn}$ nas folhas mais velhas. Os teores de $\mathrm{S}$ e Fe não variaram com a posição da folha no ramo.

\section{REFERÊNCIAS}

DALE, G.B.; KRYSTYNA, M.L. Boron in plant structure and function. Annual Review of Plant Physiology and Plant Molecular Biology, v.49, p.481-500, 1998.
DHAWAN, K. et al. Passiflora: a review update. Journal of Ethnopharmacology, v.94, p.1-23, 2004

FERNANDEZ-ESCOBAR, R. et al. Seasonal changes of mineral nutrients in olive leaves during the alternate-bearing cycle. Scientia Horticulturae, v.82, p.25-45, 1999.

JACKSON, M.L. Soil chemical analysis. New Jersey: Prentice Hall, 1965. 498p.

LANGENHEIM, C.A. et al. Leaf development in the tropical leguminous tree Copaifera in relation to microlepidopteran herbivory. Biochemical Systematics and Ecology, v.14, p.51-59, 1986.

LEITÃO, A.C., SILVA, O.A. da. Variação sazonal de macronutrientes em uma espécie arbórea do cerrado, na Reserva Biológica e Estação Experimental de Mogi-Guaçu, estado de São Paulo, Brasil. Rodriguésia, v.55, n.84, p.127-136, 2004.

LIU, Z. et al. Variation in the secondary metabolic camptothecin in relation to tissue age and sesason in C. acuminata. Tree Physiology, v.18, p.265-270, 1998.

MALAVOLTA, E. et al. Avaliação do estado nutricional das plantas: princípios e aplicações. Piracicaba: POTAFOS, 1997. 319p.

MARSCHNER, H. Mineral nutrition of higher plants. 2.ed. San Diego: Academic, 1995. 889p.

MORAES, M. de L.L. Extração e análise de flavonóides em espécies brasileiras de Passiflora L. 1995. $94 \mathrm{f}$. Dissertação (Mestrado em Ciências, área de Concentração Química Analítica) - Universidade de São Paulo- SP.

PARIS, F. de et al. Pharmacochemical study of aqueous extracts of Passilfora alata Drynder and Passiflora edulis Sims. Acta Farm Bonaerense, v.21, n.1, p.5-8, 2002.

PEREIRA, C.A.M.; VILEGAS, J.H.Y. Constituintes químicos e farmacólogicos do genêro Passiflora com ênfase a $\boldsymbol{P}$. alata Dryander, P. Edulis Sims e P. Incarnata. Revista Brasileira de Plantas Medicinais, v.3, n.1, p.1-12, 2000

PEREIRA, C.A.M. Estudos cromatográficos (HPLC, HPTLC, LC-MS) e análise microscópica das folhas de espécies de Passiflora L. 2002. 273f. Tese (Doutorado em Ciência, área de concentração Química Analítica) - USP, SP.

SANTOS, A.L. Estabelecimento de normas de amostragem foliar para avaliação do estado nutricional e adubação mineral do coqueiro anão verde na região do norte fluminense. 2002. 82f. Tese (Doutorado em Produção Vegetal) - Universidade Estadual do Norte Fluminense Darcy Ribeiro - Campos dos Goytacazes-RJ,

SOULIMANI, R. et al. Behavioral effects of Passiflora incarnata $\mathrm{L}$. and its indole alkaloid and flavonoid derivatives and maltol in the mouse. Journal of Ethpharmacology, v.57, n.1, p.11-20, 1997. 